(2) Open Access Full Text Article

\title{
Human papillomavirus (HPV): systemic treatment with Gene-Eden-VIR/Novirin safely and effectively clears virus
}

\section{Hanan Polansky \\ Edan Itzkovitz \\ Adrian Javaherian}

The Center for the Biology of Chronic Disease, Valley Cottage, NY, USA
Correspondence: Hanan Polansky The Center for the Biology of Chronic Disease, 616 Corporate Way, Suite 2-3665, Valley Cottage, NY 10989, USA

Tel +I 5852509999

Email hpolansky@cbcd.net
This article was published in the following Dove Press journal:

Drug Design, Development and Therapy

3 March 2017

Number of times this article has been viewed

Purpose: This paper reports the results of a clinical study that tested the effect of systemic treatment with the botanical product Gene-Eden-VIR/Novirin on the clearance rate (also called time to clearance) of the human papillomavirus (HPV). The study compared the clearance rate in treated and untreated individuals suffering from a symptomatic HPV infection. The data on the untreated individuals were obtained by reverse engineering of the Kaplan-Meier figures in five published papers.

Materials and methods: The study included 59 treated participants. All participants were suffering from a symptomatic HPV infection prior to the commencement of treatment. The treatment was one to four capsules of Gene-Eden-VIR/Novirin per day. The duration of treatment was 2-12 months. The study included five groups of external controls with diverse characteristics. Results: The mean time to clearance in Gene-Eden-VIR/Novirin-treated individuals was 5.1 months or 151.5 days (95\% CI: 4.2-5.9 months or 95\% CI: $125.7-177.3$ days, respectively). The median time to clearance was 3.5 months. The mean time to clearance in the five untreated groups ranged from 6.9 to 20.0 months $(P<0.0001$ for the difference between treatment group and each untreated group). Also, $100 \%$ of the participants in the treatment group were HPV free at the end of 12 months vs 53\%, 52\%, 65\%, 20\%, and 77\% in the untreated control groups. The treated participants reported no adverse experiences.

Conclusion: This clinical study has two major contributions. First, it showed that systemic treatment with the natural Gene-Eden-VIR/Novirin decreased the time to HPV clearance, increased the percentage of HPV-free individuals, and caused no adverse experiences in individuals suffering from a symptomatic HPV infection. Since there are no other systemic treatments for symptomatic HPV infections, this study presents highly valuable information on the clinical effects of the first treatment in this category. Second, the study presents a new method for conducting clinical studies that addresses one of the major deficiencies associated with the practice of the randomized controlled trial method.

Keywords: natural treatment, HPV, efficacy, safety, Gene-Eden-VIR/Novirin

\section{Introduction}

The human papillomavirus (HPV) is known to cause cancer. More than 120 different subtypes of the virus have been identified, with $\sim 40$ different subtypes capable of infecting the anogenital tract. ${ }^{1,2}$ Approximately 15 subtypes of HPV were shown to cause cervical cancer and cancers of the anus, vagina, vulva, penis, and oropharynx. ${ }^{3}$ These subtypes are called high-risk, oncogenic, or carcinogenic HPVs. ${ }^{4,5}$ In contrast, the low-risk subtypes, also called nononcogenic or noncarcinogenic, rarely cause cervical cancer, but may cause genital warts. ${ }^{1}$ 
HPV infection is mostly a transient or intermittent phenomenon, and only persistent infections may trigger the development of a carcinogenic process. Franco et al observed that $61 \%$ of subjects retained their original positivity at 6 months, but only $35 \%$ did so after 12 months. ${ }^{5}$ Furthermore, Goodman et $\mathrm{al}^{6}$ reported that low-risk HPV infections cleared more rapidly (median, 180 days in low risk vs 224 days in high risk). A total of $69 \%$ of high-risk infections and $81 \%$ of low-risk infections cleared within 1 year. In a populationbased cohort study involving 800 carcinogenic HPV infections, Rodriguez et $\mathrm{al}^{7}$ reported that 55\% (95\% CI: 52\%-59\%) and 67\% (95\% CI: 63\%-70\%) cleared by 6 and 12 months, respectively. In another study, Beachler et $\mathrm{al}^{8}$ reported that the majority of incident oral HPV infections cleared within the first year. Specifically, 83\% of incident infections and $51 \%$ of prevalent infections cleared within a year. In another population-based cohort study, Liu et $\mathrm{al}^{9}$ reported that the median time to clearance of any, oncogenic, or non-oncogenic HPV infection was 11.5, 6.8, and 11.5 months, respectively. Furthermore, $55.5 \%, 57.3 \%$, and $54.8 \%$ of any, oncogenic, and non-oncogenic HPV infections, respectively, were cleared 12 months after new acquisition of infection.

Currently, there are no systemic treatments for symptomatic HPV infections. The only available options are local, provider-, and patient-applied treatments, which remove the abnormal HPV-induced growths. ${ }^{10,11}$ These treatments have no effect on the clearance of HPV.

Gene-Eden-VIR/Novirin is a patented botanical systemic treatment consisting of the following five natural ingredients: quercetin $100 \mathrm{mg}$, green tea extract $150 \mathrm{mg}$, cinnamon extract $50 \mathrm{mg}$, selenium $100 \mu \mathrm{g}$, and licorice extract $25 \mathrm{mg}$. GeneEden-VIR/Novirin was developed to target latent viruses, including herpes simplex virus (HSV), human papillomavirus (HPV), cytomegalovirus (CMV), and Epstein Barr Virus (EBV), and diminish their deleterious effect on the host, as explained by the microcompetition theory. ${ }^{12-14}$

The team that developed the Gene-Eden-VIR/Novirin formula used Computer Intuition, a proprietary psycholinguistic-based, data-mining program that analyzes text found in scientific papers and other reports. ${ }^{15}$ The team's objective was to find natural compounds with a strong antiviral effect. Through the development process, the team used Computer Intuition to analyze $>50,000$ papers. The results of the computer analysis assisted the team in creating the Gene-Eden-VIR/Novirin formula.

Gene-Eden-VIR/Novirin was launched at the end of 2009. The Center for the Biology of Chronic Disease (CBCD) published the first clinical study of Gene-Eden-VIR/Novirin in 2013. The study showed that Gene-Eden-VIR/Novirin has antiviral properties. ${ }^{15}$ The CBCD published a second clinical study in 2014. This study showed that Gene-Eden-VIR/ Novirin safely decreased the feeling of fatigue in individuals infected with a latent virus. ${ }^{16}$ A third clinical study was published in 2016 that showed that Gene-Eden-VIR/Novirin decreased the number of genital herpes outbreaks without any side effects. ${ }^{17}$ It also showed that the clinical effects of Gene-Eden-VIR/Novirin are mostly better than those reported in the studies that tested acyclovir, valacyclovir, and famciclovir, the three leading antiviral drugs. A fourth clinical study showed that Gene-Eden-VIR/Novirin decreased the duration of genital herpes outbreaks. ${ }^{18}$

This study reports the results of a clinical study that tested the effect of systemic treatment with Gene-Eden-VIR/ Novirin on the clearance rate of HPV in individuals suffering from a symptomatic HPV infection.

\section{Materials and methods Objective}

The objective of this clinical study was to test the effect of systemic treatment with Gene-Eden-VIR/Novirin on the clearance rate, or time to clearance, of HPV in individuals suffering from a symptomatic HPV infection.

\section{Framework}

The framework was a retrospective chart review. Lilac Corp, the company that sells Gene-Eden-VIR/Novirin, provides a service to the customers who purchased the products. The service consists of tracking the changes in the customers' health while using the products. The company uses a questionnaire called the Natural Origin Treatment Clinical Questionnaire (NotCiq). The data are collected over the phone by professional interviewers in a single session. The NotCiq is a patient-reported outcome (PRO) instrument. These sessions produced the charts that were analyzed in this study. More details on the NotCiq are available in our previous paper. ${ }^{15}$

\section{Randomization}

A random selection of charts, collected during a 2-month period, October and November 2015, were analyzed. The 2 months were randomly selected.

\section{Treatment}

The treatment was one, two, three, or four capsules of GeneEden-VIR/Novirin per day. The duration of treatment ranged from 2 to 12 months. The mean duration of treatment was 5.1 months. The treatment group included 59 participants. The study included five external controls consisting of 123 , 68, 197, 144, and 95 participants. 


\section{Selection of external controls}

A search was conducted on PubMed database for papers reporting studies conducted on patients with HPV infection that included a clear Kaplan-Meier figure that reported the percentage of individuals who remained HPV positive after a certain period of time. The following title/abstract keywords were used: "human papillomavirus", "hpv", "clearance", and "cleared". No date restrictions were applied. The final list included five papers. ${ }^{5,9,19-21}$ When multiple groups were represented in a single figure or multiple figures, we selected the group with the shortest time to clearance as the external control.

\section{Data extraction through reverse engineering}

Since the data representing the external controls could only be obtained in figures, we performed reverse engineering to convert these figures to numbers that can be analyzed statistically. ${ }^{22,23}$ First, we carefully selected the pixel coordinates of each figure to capture all variations depicted in the curve. Then, we entered these coordinates into a mathematical formula to calculate the number of people surviving at the end of each period, in our case, the number of people remaining HPV positive. To check the accuracy of the reverse-engineering process, we entered these numbers into a statistical software that performed a Kaplan-Meier analysis. The software calculated the mean and median survival times along with their confidence intervals. We then compared the calculated statistics with those reported in the original papers. We also compared the reverse-engineered Kaplan-Meier figures with the original figures.

\section{Outcome measures}

The NotCiq for HPV infection has several sections, including a section on demographics, a section on treatment, a section on diagnosis, a section on symptoms, a section on follow-up, and a section on clearance. The answers to the NotCiq were collected in single-session phone interviews by four independent interviewers who specialize in outbound call services. The interviewers were blinded to the objective of the study.

\section{Efficacy}

The primary end points were the mean and median times to clearance of HPV infection. Clearance time was defined as the time the doctor told the participant that he or she is clear of the virus.

\section{Safety}

The participants' reports of adverse events were collected and analyzed.

\section{Population}

Participants who were using Gene-Eden-VIR/Novirin for other purposes, such as treatment for cancer, chronic diseases, and hypertension, were excluded. Participants concurrently taking antiviral medications as suppressive treatment were also excluded. The final list of participants consisted of 59 men and women aged $\geq 18$ years suffering from a symptomatic HPV infection.

\section{Ethical consideration}

The study was approved by the Salus Institutional Review Board (IRB). The IRB approved a waiver of the requirement to obtain an informed consent from the participants. The trial is registered on ClinicalTrials.gov (identifier: NCT02715752).

\section{Statistical analysis}

The analysis was based on the intent-to-treat (all participants randomized) population. We analyzed the duration of infection and time to clearance (clearance rate) using the KaplanMeier product-limit method, and the differences between the treatment and each of the control groups were evaluated by log-rank, Wilcoxon, and Tarone-Ware tests. The $P \leq 0.05$ value was considered as statistically significant.

\section{Results \\ Patient demographic and baseline characteristics}

A total of 59 participants were included in the study. Table 1 summarizes the demographic and clinical characteristics of these participants. According to Liu et al, ${ }^{24}$ the seroprevalence rates of HPV types 16/18/31/33/45/52/58 in non-Hispanic whites and non-Hispanic blacks are $16.9 \%$ and $33.5 \%$, respectively. Therefore, considering the percentage of these races in the American population ( $63.7 \%$ vs $12.2 \%$, respectively), the ratio between non-Hispanic whites to non-Hispanic blacks in a representative sample should be 2.63. In this study, the ratio is 2.85 . Also, according to Liu et $\mathrm{al},{ }^{24}$ the seroprevalence rates of HPV types 6/11/16/18/31/33/45/52/58 are $40 \%$ in females and $20 \%$ in males. In this study, the ratio between females and males is 2.1 .

\section{Reverse engineering}

First, we juxtaposed the reverse-engineered Kaplan-Meier plot of each external control with the original plot to verify the accuracy of the reverse-engineering process (Figure 1). We then compared the reverse-engineered time to clearance statistics with that mentioned in the papers, when available. Table 2 presents the results of the comparison. 
Table I Demographic and clinical characteristics of the participants

\begin{tabular}{ll}
\hline Characteristic & Years/n/\% \\
\hline Age - average (years) & 47 \\
Age, years $-\mathrm{n}(\%)$ & \\
$20-40$ & $21(35.6)$ \\
$4 \mathrm{I}-50$ & $13(22.0)$ \\
$5 \mathrm{I}-60$ & $11(18.6)$ \\
$6 \mathrm{I}-80$ & $14(23.7)$ \\
Gender $-\mathrm{n}(\%)$ & \\
Male & $19(32.2)$ \\
Female & $40(67.8)$ \\
Race $-\mathrm{n}$ (\%) & \\
African American & $13(22.0)$ \\
Caucasian & $37(62.7)$ \\
Hispanic & $5(8.5)$ \\
Others & $4(6.8)$ \\
Symptoms of infection $-\mathrm{n}$ (\%) & \\
Genital warts & $27(45.8)$ \\
Oral warts & $4(6.8)$ \\
Cutaneous warts & $12(20.3)$ \\
Bleeding after sexual intercourse & $3(5.1)$ \\
Pain sensation after sexual intercourse & $5(8.5)$ \\
Vaginal bleeding between periods & $4(6.8)$ \\
Sensation of fullness in the pelvis & $6(10.2)$ \\
Anus or rectal bleeding & $3(5.1)$ \\
Genital itching sensation & $16(27.1)$ \\
\hline
\end{tabular}

\section{Efficacy}

Based on the 59 participants in this study, the mean time to clearance (clearance rate) was 5.1 months or 151.5 days (95\% CI: 4.2-5.9 months, or 95\% CI: 125.7-177.3 days). The median time to clearance was 3.5 months. The mean time to clearance in the five untreated groups ranged from 6.9 to 20.0 months (Table 2). A statistical analysis comparing the results in the current study with each of the five controls, using log-rank, Wilcoxon, and Tarone-Ware tests, showed that the difference is statistically significant $(P<0.0001$ for each comparison and each test). The results also showed that $100 \%$ of the participants in the treatment group were HPV free at the end of 12 months vs $53 \%, 52 \%, 65 \%, 20 \%$, and $77 \%$ in the control groups. The results also showed that treatment with Gene-Eden-VIR/Novirin decreased the time to clearance by an average of $57.2 \%$ relative to the control groups (Table 3).

We also compared, graphically, the time to clearance in the current study to that in the external controls (Figure 2). The Kaplan-Meier figures clearly show that treatment with Gene-Eden-VIR/Novirin is associated with faster clearance (higher clearance rate) compared to each of the untreated external controls.

\section{Reliability}

Table 4 summarizes the populations in the five experiments.
The five external controls had different populations (Table 4). Yet in all five cases, treatment with Gene-EdenVIR/Novirin showed a statistically significant decrease in time to clearance relative to the controls, that is, faster clearance and more effective clearance at the tested time. The scientific method argues in favor of randomization, large sample sizes, independent verification by different laboratories, etc. to even out specific peculiarities inherited in any specific study, that is, to mitigate the effect of co-founding factors. Science considers the same result under dissimilar settings as reliable. This study showed that the effect of Gene-Eden-VIR/Novirin is significant when compared to a variety of untreated groups with dissimilar characteristics. Therefore, we conclude that the observed effect is, most likely, real, that is, not an artifact of the specific treatment population or its matching specific controls, and, therefore, with strong external validity. The diverse characteristics of the populations in this study increase the level of confidence in the effectiveness of the tested treatment.

\section{Safety}

The participants reported no adverse effects.

\section{Discussion}

This clinical study showed that systemic treatment with Gene-Eden-VIR/Novirin decreased the time to clearance and increased the percentage of HPV-free individuals in those suffering from a symptomatic HPV infection. The treated participants reported no adverse experiences. In other words, the clinical study showed that systemic treatment with the natural Gene-Eden-VIR/Novirin is a safe and effective treatment for symptomatic HPV infections.

Our study did not attempt to measure the effect of GeneEden-VIR/Novirin on HPV itself, but the symptoms it causes. Yet, a better understanding of the Gene-Eden-VIR/Novirin mechanism of action is important. Such an understanding can be gleaned from some of the following in vitro studies that tested the effects of the Gene-Eden-VIR/Novirin ingredients on the virus.

In one study, Vidya et $\mathrm{al}^{25}$ reported that quercetin suppressed the viability of human cervical cancer cells by inducing $\mathrm{G} 2 / \mathrm{M}$ phase cell cycle arrest and mitochondrial apoptosis through a p53-dependent mechanism. Another mechanism of action against HPV involves the inhibition of transcription of HPV viral proteins by antioxidants, including epigallocatechin gallate (EGCG), the lead catechin of green tea. ${ }^{26}$ Furthermore, in another study, Doan et $\mathrm{al}^{27}$ determined that treatment with green tea extract modulates and downregulates genes 

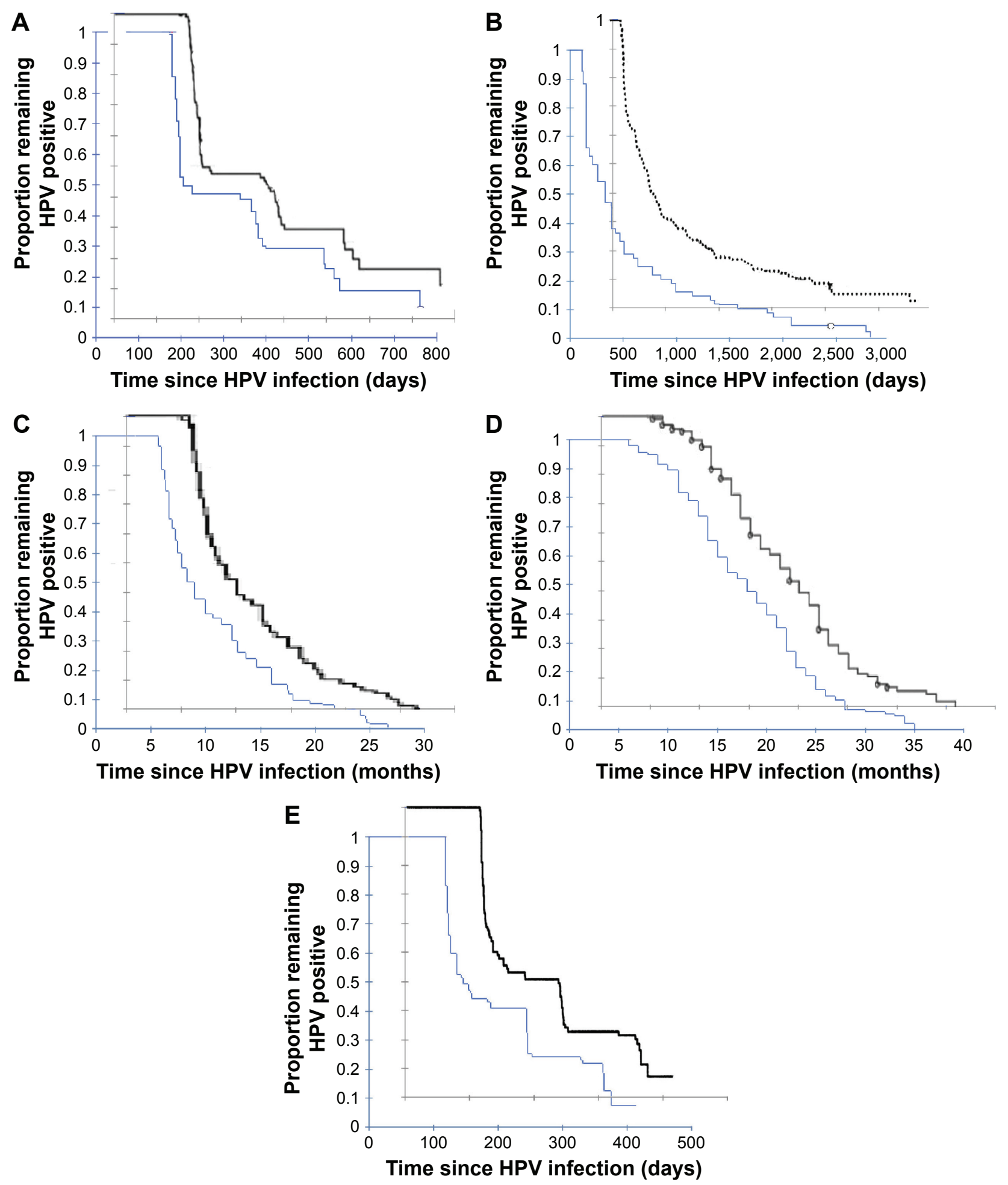

Figure I Reverse-engineered figures (blue curves) vs. original figures (black curves).

Notes: The survival distribution curve of each reverse-engineered external control plotted against that of the original figure from the five papers: (A) Liu et al (Reprinted by permission from the American Association for Cancer Research: Liu M, He Z, Zhang C, etal. Prevalence, incidence, clearance, and associated factors of genital human papillomavirus infection among men: a population-based cohort study in rural China. Cancer Epidemiol Biomarkers Prev. 201 4;23( (2):2857-28659), (B) Moscicki et al (Moscicki AB, Ma Y, Farhat S, et al. Natural history of anal human papillomavirus infection in heterosexual women and risks associated with persistence. Clin Infect Dis. 2014;58(6):804-8I I, by permission of Oxford University Press ${ }^{19}$ ), (C) Munoz et al (Reprinted by permission from Macmillan Publishers Ltd: British Journal of Cancer http://www.nature.com/bjc/index.html. Munoz N, Hernandez-Suarez G, Mendez F, et al. Persistence of HPV infection and risk of high-grade cervical intraepithelial neoplasia in a cohort of Colombian women. Br J Cancer. 2009;100(7): I 184-I 190, copyright 2009.20), (D) Rosa et al (Reprinted from Am J Obstet Gynecol, 199(617), Rosa MI, Fachel JM, Rosa DD, Medeiros LR, Igansi CN, Bozzetti MC. Persistence and clearance of human papillomavirus infection: a prospective cohort study, el-e7, Copyright (2008), with permission from Elsevier $\left.{ }^{21}\right)$, and (E) Franco et al (Franco EL, Villa LL, Sobrinho JP, et al. Epidemiology of acquisition and clearance of cervical human papillomavirus infection in women from a high-risk area for cervical cancer. J Infect Dis. 1999; 180(5): 1415-1423, by permission of Oxford University Press ${ }^{5}$ ).

Abbreviation: HPV, human papillomavirus. 
Table 2 Reverse-engineered vs original figures and statistics in the five papers

\begin{tabular}{|c|c|c|c|}
\hline Study & $\mathbf{n}$ & Time to clearance (reverse engineered ${ }^{a}$ ) & $\begin{array}{l}\text { Time to clearance (actual, from } \\
\text { paper) }\end{array}$ \\
\hline Liu et $\mathrm{al}^{9}$ & $123^{\mathrm{a}}$ & $\begin{array}{l}\text { Mean: } 12.1 \text { months ( } 95 \% \mathrm{Cl} \text { : } 10.8-13.3 \text { days) } \\
\text { Median: } 6.8 \text { months }\end{array}$ & $\begin{array}{l}\text { Median: } 6.8 \text { months ( } 95 \% \mathrm{Cl}: 6.4-12.6 \\
\text { months) }\end{array}$ \\
\hline Moscicki et al ${ }^{19}$ & $68^{\mathrm{a}}$ & Mean: 600.4 days ( 20 months, $95 \% \mathrm{Cl}: 436 . \mathrm{I}-764.8$ days) & 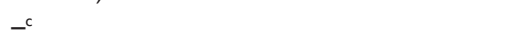 \\
\hline Munoz et $\mathrm{al}^{20}$ & $197^{b}$ & Mean: I I.0 months ( $95 \% \mathrm{Cl}$ : $0.2-11.7$ months) & $-^{c}$ \\
\hline Rosa et $\mathrm{a}^{21}$ & $144^{b}$ & Mean: I8.5 months ( $95 \% \mathrm{Cl}$ : 17.3-19.6 months) & $-^{c}$ \\
\hline Franco et $\mathrm{a}^{5}$ & $95^{\mathrm{b}}$ & Mean: 6.9 months (95\% Cl: $6.2-7.6$ months) & Mean: 7.0 months (95\% Cl: $6.2-7.8$ months) \\
\hline
\end{tabular}

Notes: aSample size taken directly from the paper. 'Sample size calculated from data in the paper. 'No matching statistics found in the paper.

involved in the proinflammatory response to HPV infection. In addition, inhibition of HPV binding to receptors as well as signal transduction modification, including inhibition of receptor tyrosine kinases, may add to the pharmacological effect of green tea in Gene-Eden-VIR/Novirin. ${ }^{26,28}$

These in vitro studies show that the Gene-Eden-VIR/ Novirin ingredients have many effects on HPV-infected cells. The additive effect of these mechanisms might explain how Gene-Eden-VIR/Novirin achieves its clinical objectives with the surprisingly low dosages of its five ingredients. Moreover, the many mechanisms highlight an important aspect of the Gene-Eden-VIR/Novirin therapy. Gene-EdenVIR/Novirin has multiple targets. In other words, GeneEden-VIR/Novirin operates on many targets rather than inhibiting one molecule.

This study used patient reported outcomes (PROs). Many studies use PROs to collect clinical data. ${ }^{29}$ In fact, of the 96,736 clinical trials registered in the ClinicalTrials.gov database between November 2007 and December 2013, 26,337 or $27 \%$ used at least one PRO measure. ${ }^{30}$ ClinicalTrials.gov is just the tip of the iceberg. Many major medical journals routinely publish clinical studies that use PROs. Also, in the last few years, PROs had a major impact on the research and development and evaluation of new drugs. ${ }^{31}$ For instance, between 1997 and 2002, the US Food and Drug Administration (FDA) used PROs in evaluating and approving the label claims of 23 new drugs. These drugs include anti-migraine drugs $\left(\right.$ Amerge $^{\circledR}$, Axert $^{\circledR}$ ), anti-epileptic drugs (Gabitril ${ }^{\circledR}$, Keppra $^{\circledR}$ ), and drugs of other classes $\left(\right.$ Tamiflu $^{\circledR}$, Relenza ${ }^{\circledR}$ ).
This clinical study does not include an internal placebo control. Many pre-marketing clinical studies use such controls. However, post-marketing studies almost never use placebo controls. They use other types of controls. The FDA guidance recommends six types of controls: 1) placebo concurrent control; 2) no-treatment concurrent control; 3) doseresponse concurrent control; 4) active (positive) concurrent control; 5) external control (including historical control and baseline-controlled studies); and 6) multiple control groups. ${ }^{32}$ This post-marketing clinical study included five external controls.

Randomized controlled trials (RCTs) are regarded as the gold standard in clinical research. A known problem with RCTs is their perceived limited external validity (or generalizability). To measure the external validity of published RCTs in asthma, a study ${ }^{33}$ carried out a survey of 3,500 randomly selected individuals aged 25-75 years. Then, the study assessed the participants with asthma against the eligibility criteria of the 17 major asthma RCTs cited in the Global Initiative for Asthma (GINA) guidelines. The results showed that only $4 \%$ of participants with current asthma and $6 \%$ with current asthma on treatment met the eligibility criteria for the 17 RCTs. The study concluded that "most of the participants with current asthma on treatment in the community would not have been eligible for these RCTs." More specifically, the study found that the 17 RCTs relied upon in formulating the guidelines for treatment were irrelevant to $>94 \%$ of the asthma patients in the community. Such gross lack of relevance, or external validity, pushes

Table 3 Clearance rate following treatment with Gene-Eden-VIR/Novirin vs untreated external controls

\begin{tabular}{|c|c|c|c|}
\hline Study & $\mathbf{n}$ & $\begin{array}{l}\text { Time to clearance (reverse engineered; } \\
\text { untreated) }\end{array}$ & $\begin{array}{l}\% \text { decrease in time to } \\
\text { clearance (treated) }\end{array}$ \\
\hline Liu et $\mathrm{al}^{9}$ & $123^{a}$ & Mean: I2.I months (95\% Cl: I0.8-13.3 months) & 57.9 \\
\hline Moscicki et al ${ }^{19}$ & $68^{\mathrm{a}}$ & Mean: 600.4 days ( 20 months; $95 \% \mathrm{Cl}: 436.1-764.8$ days) & 74.8 \\
\hline Munoz et $\mathrm{al}^{20}$ & $197^{\mathrm{b}}$ & Mean: I I.0 months (95\% Cl: I0.2-II.7 months) & 53.6 \\
\hline Rosa et $\mathrm{al}^{21}$ & $144^{b}$ & Mean: 18.5 months ( $95 \% \mathrm{Cl}$ : 17.3-19.6 months) & 72.4 \\
\hline Franco et $\mathrm{al}^{5}$ & $95^{\mathrm{b}}$ & Mean: 6.9 months ( $95 \% \mathrm{Cl}: 6.2-7.6$ months) & 27.1 \\
\hline Current study & 59 & Mean: 5.1 months (95\% Cl: $4.2-5.9$ months) & Average: 57.2 \\
\hline
\end{tabular}

Notes: asample size taken directly from the paper. ${ }^{b}$ Sample size calculated from data in the paper. 
A

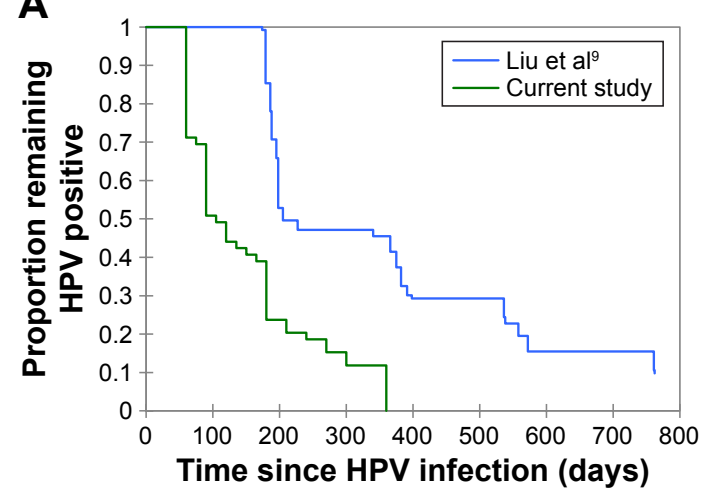

C

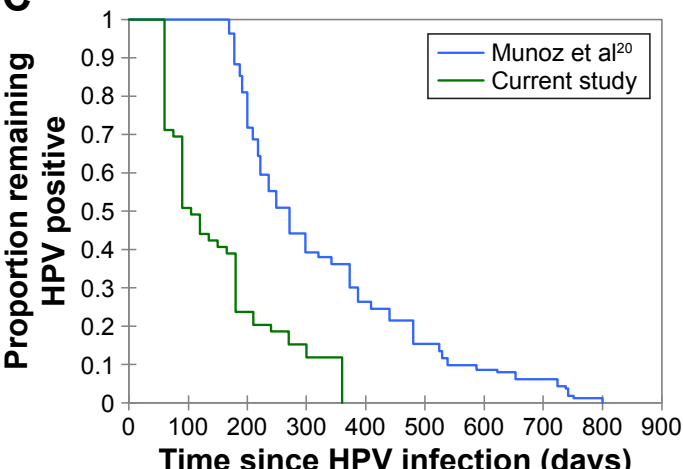

B

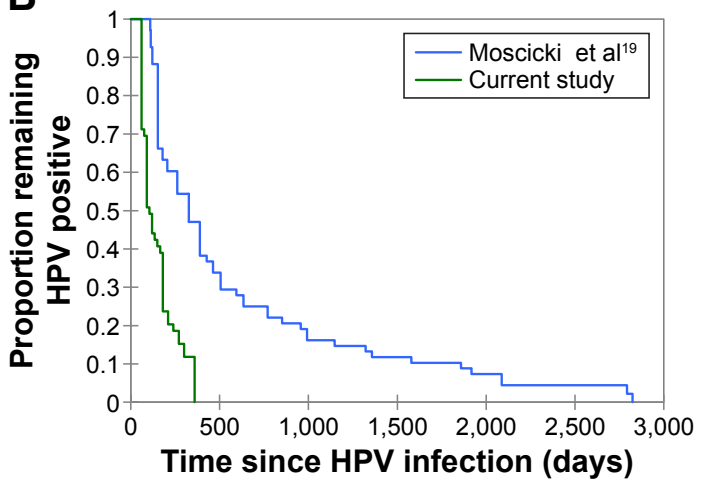

D

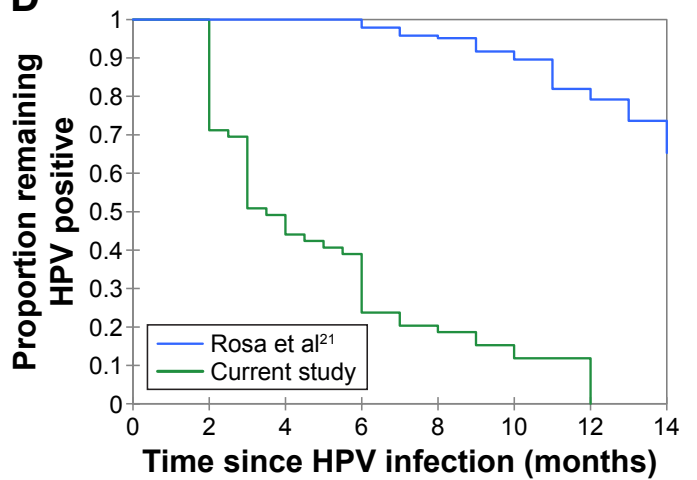

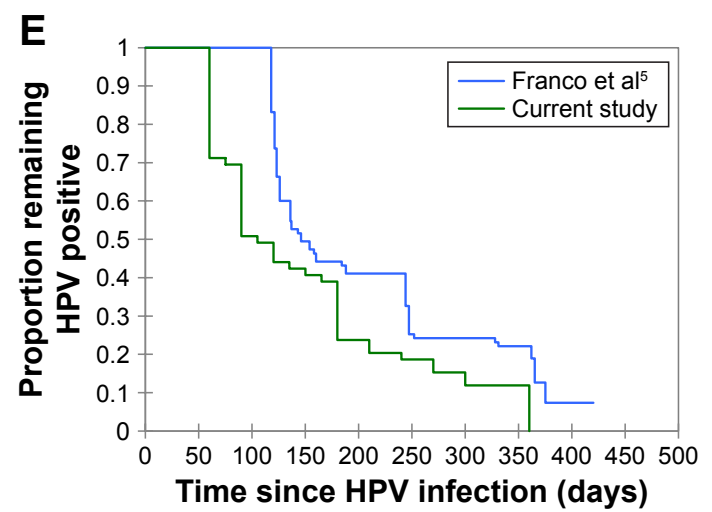

Figure 2 Reversed engineered (blue curve) vs. current study (green curve).

Notes: The survival distribution curve of the current study against each of the external controls: (A) Liu et al (Adapted by permission from the American Association for Cancer Research: Liu M, He Z, Zhang C, et al. Prevalence, incidence, clearance, and associated factors of genital human papillomavirus infection among men: a population-based cohort study in rural China. Cancer Epidemiol Biomarkers Prev. 20I4;23(I2):2857-2865'), (B) Moscicki et al (Moscicki AB, Ma Y, Farhat S, et al. Natural history of anal human papillomavirus infection in heterosexual women and risks associated with persistence. Clin Infect Dis. 20I4;58(6):804-8I I, by permission of Oxford University Press ${ }^{19}$ ), (C) Munoz et al (Adapted by permission from Macmillan Publishers Ltd: British Journal of Cancer http://www.nature.com/bjc/index.html. Munoz N, Hernandez-Suarez G, Mendez F, et al. Persistence of HPV infection and risk of high-grade cervical intraepithelial neoplasia in a cohort of Colombian women. Br J Cancer. 2009; I00(7): I I84-I I 90, copyright 2009.20), (D) Rosa et al (Adapted from Am J Obstet Gynecol, 199(6I7), Rosa MI, Fachel JM, Rosa DD, Medeiros LR, Igansi CN, Bozzetti MC. Persistence and clearance of human papillomavirus infection: a prospective cohort study, e I-e7, Copyright (2008), with permission from Elsevier ${ }^{21}$ ), and (E) Franco et al (Franco EL, Villa LL, Sobrinho JP, et al. Epidemiology of acquisition and clearance of cervical human papillomavirus infection in women from a high-risk area for cervical cancer. J Infect Dis. 1999; 180(5): 1415-1423, by permission of Oxford University Press 5 ).

Abbreviation: HPV, human papillomavirus.

Table 4 Summary of the population in the five external controls and treatment group

\begin{tabular}{|c|c|c|c|c|c|}
\hline Study & $\mathbf{n}$ & Gender & Ethnicity & High/low risk ${ }^{a}$ & Incident/prevalent ${ }^{b}$ \\
\hline Liu et $\mathrm{al}^{9}$ & 123 & Men & Chinese & High & Incident \\
\hline Moscicki et al ${ }^{19}$ & 68 & Women & Caucasian, African American, Hispanic, Asian, others & Low & Prevalent \\
\hline Munoz et $\mathrm{a}^{20}$ & 197 & Women & Colombian & Low & Incident \\
\hline Rosa et $\mathrm{al}^{21}$ & 144 & Women & Brazilian & High and low & Prevalent \\
\hline Franco et $\mathrm{al}^{5}$ & 95 & Women & Brazilian & Low & Incident \\
\hline Current study & 59 & Men and women & Caucasian, African American, Hispanic, others & High and low & Prevalent \\
\hline
\end{tabular}

Notes: a We chose the fastest time to clearance in the study. ${ }^{\mathrm{b}} \mathrm{An}$ incident HPV infection means HPV negative at baseline. ${ }^{22} \mathrm{~A}$ prevalent HPV infection means HPV positive at baseline.

Abbreviation: HPV, human papillomavirus. 
clinicians to ask "whether the results (of these and published RCTs) can be reasonably applied to a definable group of patients in a particular clinical setting in routine practice". ${ }^{34}$ According to Rothwell, ${ }^{34}$ "there is concern among clinicians that external validity (of the published RCTs) is often poor, particularly for some pharmaceutical industry trials." To summarize, we agree that the ideal form of the RCT method is indeed the gold standard in clinical research. But the form implemented in actual clinical research is different from the ideal. An RCT is easy to manipulate (refer the study by Every-Palmer and Howick, ${ }^{35}$ specifically, "Box 1: Examples of methods for pharmaceutical companies to get the results they want from clinical trials"), and scientists are not angels. Scientists are people with agendas. As a result, we need a method that fits people, that is, a method that is less susceptible to manipulation. We believe that this study introduces such a method.

In our study, we used five external controls, each with a distinct group of HPV-infected individuals. The study showed that treatment with Gene-Eden-VIR/Novirin increases the clearance rate in a diversified group of individuals relative to another diversified group of individuals. In contrast to some RCTs, which used narrowly defined participants, this study uses diversified treatment and control groups, which we believe represent well the target population. As a result, we propose that this study may have higher external validity or generalizability than many published RCTs.

\section{Conclusion}

This clinical study has two major contributions. First, it showed that systemic treatment with the natural GeneEden-VIR/Novirin decreased the time to HPV clearance, increased the percentage of HPV-free individuals, and caused no adverse experiences in individuals suffering from a symptomatic HPV infection. Since there are no other systemic treatments for symptomatic HPV infections, this study presents highly valuable information on the clinical effects of the first treatment in this category. Second, the study presents a new method for conducting clinical studies that addresses one of the major deficiencies associated with the practice of the RCT method.

\section{Acknowledgment}

There was no funding for this manuscript.

\section{Disclosure}

The authors report no conflicts of interest in this work.

\section{References}

1. Doorbar J. Molecular biology of human papillomavirus infection and cervical cancer. Clin Sci (Lond). 2006;110(5):525-541.

2. Yanofsky VR, Patel RV, Goldenberg G. Genital warts: a comprehensive review. J Clin Aesthet Dermatol. 2012;5(6):25-36.

3. Moscicki A-B, Palefsky JM. HPV in men: an update. J Low Genit Tract Dis. 2011;15(3):231-234.

4. Schiffman M, Castle PE, Jeronimo J, Rodriguez AC, Wacholder S. Human papillomavirus and cervical cancer. Lancet. 2007;370(9590): 890-907.

5. Franco EL, Villa LL, Sobrinho JP, et al. Epidemiology of acquisition and clearance of cervical human papillomavirus infection in women from a highrisk area for cervical cancer. J Infect Dis. 1999;180(5):1415-1423.

6. Goodman MT, Shvetsov YB, McDuffie K, et al. Prevalence, acquisition, and clearance of cervical human papillomavirus infection among women with normal cytology: Hawaii Human Papillomavirus Cohort Study. Cancer Res. 2008;68(21):8813-8824.

7. Rodriguez AC, Schiffman M, Herrero R, et al. Rapid clearance of human papillomavirus and implications for clinical focus on persistent infections. J Natl Cancer Inst. 2008;100(7):513-517.

8. Beachler DC, Sugar EA, Margolick JB, et al. Risk factors for acquisition and clearance of oral human papillomavirus infection among HIV-infected and HIV-uninfected adults. Am J Epidemiol. 2015;181(1):40-53.

9. Liu M, He Z, Zhang C, et al. Prevalence, incidence, clearance, and associated factors of genital human papillomavirus infection among men: a population-based cohort study in rural China. Cancer Epidemiol Biomarkers Prev. 2014;23(12):2857-2865.

10. Park IU, Introcaso C, Dunne EF. Human papillomavirus and genital warts: a review of the evidence for the 2015 Centers for Disease Control and prevention sexually transmitted diseases treatment guidelines. Clin Infect Dis. 2015;61(suppl 8):S849-S855.

11. de Lima MM Jr, de Lima MM, Granja F. Treatment of genital lesions with diode laser vaporization. BMC Urol. 2015;15:39.

12. Polansky H, Javaherian A. 3-Econsystems: microRNAs, receptors, and latent viruses: some insights biology can gain from economic theory. Front Microbiol. 2016;7:369.

13. Polansky H, Javaherian A. Commentary: the unliganded glucocorticoid receptor positively regulates the tumor suppressor gene BRCA1 through GABP beta. Front Cell Infect Microbiol. 2015;5:66.

14. Polansky H. Microcompetition with Foreign DNA and the Origin of Chronic Disease. New York: CBCD Publishing; 2003.

15. Polansky H, Itzkovitz E. Gene-Eden-VIR is antiviral: results of a Post Marketing Clinical Study. Pharmacol Pharm. 2013;4(6A):1-8.

16. Polansky H, Itzkovitz E. Gene-Eden-VIR decreased physical and mental fatigue in a Post Marketing Clinical Study that followed FDA guidelines; results support microcompetition theory. Pharmacol Pharm. 2014;5(3):280-290.

17. Polansky H, Javaherian A, Itzkovitz E. Clinical study in genital herpes: natural gene-Eden-VIR/Novirin versus acyclovir, valacyclovir, and famciclovir. Drug Des Devel Ther. 2016;10:2713-2722.

18. Polansky H, Javaherian A, Itzkovitz E. Clinical Study of gene-EdenVIR/Novirin in genital herpes: suppressive treatment safely decreases the duration of outbreaks in both severe and mild cases. Clin Transl Med. 2016;5(1):40.

19. Moscicki AB, Ma Y, Farhat S, et al. Natural history of anal human papillomavirus infection in heterosexual women and risks associated with persistence. Clin Infect Dis. 2014;58(6):804-811.

20. Munoz N, Hernandez-Suarez G, Mendez F, et al. Persistence of HPV infection and risk of high-grade cervical intraepithelial neoplasia in a cohort of Colombian women. Br J Cancer. 2009;100(7):1184-1190.

21. Rosa MI, Fachel JM, Rosa DD, Medeiros LR, Igansi CN, Bozzetti MC. Persistence and clearance of human papillomavirus infection: a prospective cohort study. Am J Obstet Gynecol. 2008;199(617):e1-e7.

22. Liu Z, Rich B, Hanley JA. Recovering the raw data behind a nonparametric survival curve. Syst Rev. 2014;3:151. 
23. Guyot P, Ades AE, Ouwens MJ, Welton NJ. Enhanced secondary analysis of survival data: reconstructing the data from published KaplanMeier survival curves. BMC Med Res Methodol. 2012;12:9.

24. Liu G, Markowitz LE, Hariri S, Panicker G, Unger ER. Seroprevalence of 9 human papillomavirus types in the United States, 2005-2006. J Infect Dis. 2016;213(2):191-198.

25. Vidya PR, Senthil MR, Maitreyi S, Ramalingam K, Karunagaran D, Nagini $S$. The flavonoid quercetin induces cell cycle arrest and mitochondria-mediated apoptosis in human cervical cancer (HeLa) cells through p53 induction and NF-kB inhibition. Eur J Pharmacol. 2010;649(1-3):84-91.

26. Sinha S, Relhan V, Garg VK. Immunomodulators in warts: unexplored or ineffective? Indian J Dermatol. 2015;60(2):118-129.

27. Doan HQ, Nguyen HP, Rady P, Tyring SK. Expression patterns of immune-associated genes in external genital and perianal warts treated with sinecatechins. Viral Immunol. 2015;28(4):236-240.

28. Balaji G. Sinecatechins: a better prospect for treating anogenital warts. Indian J Sex Transm Dis. 2014;35(1):75-76.

29. Calvert M, Kyte D, Duffy H, et al. Patient-reported outcome (PRO) assessment in clinical trials: a systematic review of guidance for trial protocol writers. PLoS One. 2014;9(10):e110216.

30. Vodicka E, Kim K, Devine EB, Gnanasakthy A, Scoggins JF, Patrick DL. Inclusion of patient-reported outcome measures in registered clinical trials: evidence from ClinicalTrials.gov (2007-1013). Contemp Clin Trials. 2015;43:1-9.
31. Willke RJ, Burke LB, Erickson P. Measuring treatment impact: a review of patient-reported outcomes and other efficacy endpoints in approved product labels. Control Clin Trials. 2004;25(6):535-552.

32. US Department of Health and Human Services, Food and Drug Administration, Center for Drug Evaluation and Research (CDER) Guidance for industry, E 10 choice of control group and related issues in clinical trials. 2001. Available from: http://www.fda.gov/downloads/drugs/ guidancecomplianceregulatoryinformation/guidances/ucm073139.pdf. Accessed August 16, 2016.

33. Travers J, Marsh S, Williams M, et al. External validity of randomised controlled trials in asthma: to whom do the results of the trials apply? Thorax. 2007;62(3):219-223.

34. Rothwell PM. External validity of randomised controlled trials: "To whom do the results of this trial apply?" Lancet. 2005;365(9453):82-93.

35. Every-Palmer S, Howick J. How evidence-based medicine is failing due to biased trials and selective publication. J Eval Clin Pract. 2014; 20(6):908-914.

\section{Publish your work in this journal}

Drug Design, Development and Therapy is an international, peerreviewed open-access journal that spans the spectrum of drug design and development through to clinical applications. Clinical outcomes, patient safety, and programs for the development and effective, safe, and sustained use of medicines are the features of the journal, which has also been accepted for indexing on PubMed Central. The manuscript management system is completely online and includes a very quick and fair peer-review system, which is all easy to use. Visit http://www.dovepress.com/testimonials.php to read real quotes from published authors.

Submit your manuscript here: http://www.dovepress.com/drug-design-development-and-therapy-journal 